OPEN ACCESS

Edited by:

Vicent Arbona

Jaume I University, Spain

Reviewed by:

Roel C. Rabara,

New Mexico Consortium,

United States

Walter Chitarra,

Consiglio per la Ricerca in Agricoltura e l'Analisi dell'Economia Agraria

(CREA), Italy

*Correspondence:

Carla António

antonio@itqb.unl.pt

Specialty section: This article was submitted to

Plant Abiotic Stress,

a section of the journal

Frontiers in Plant Science

Received: 17 May 2017 Accepted: 30 November 2017 Published: 14 December 2017

Citation:

Duvane JA, Jorge TF, Maquia I, Ribeiro N, Ribeiro-Barros AIF and António C (2017) Characterization

of the Primary Metabolome

of Brachystegia boehmii

and Colophospermum mopane under Different Fire Regimes in Miombo and Mopane African Woodlands.

Front. Plant Sci. 8:2130.

doi: 10.3389/fpls.2017.02130

\section{Characterization of the Primary Metabolome of Brachystegia boehmii and Colophospermum mopane under Different Fire Regimes in Miombo and Mopane African Woodlands}

\author{
Jossias A. Duvane ${ }^{1,2}$, Tiago F. Jorge'2, Ivete Maquia ${ }^{3}$, Natasha Ribeiro ${ }^{4}$, \\ Ana I. F. Ribeiro-Barros ${ }^{2,5}$ and Carla António ${ }^{2 *}$
}

${ }^{1}$ Faculty of Sciences, Eduardo Mondlane University, Maputo, Mozambique, ${ }^{2}$ Plant Metabolomics Laboratory, Instituto de Tecnologia Química e Biológica António Xavier, Universidade Nova de Lisboa, Oeiras, Portugal, ${ }^{3}$ Biotechnology Center, Maputo, Mozambique, ${ }^{4}$ Faculty of Agronomy and Forest Engineering, Eduardo Mondlane University, Maputo, Mozambique, ${ }^{5}$ Plant Stress and Biodiversity Laboratory, Linking Landscape, Environment, Agriculture and Food, Instituto Superior de Agronomia, Universidade de Lisboa, Lisboa, Portugal

Miombo and Mopane are ecological and economic important woodlands from Africa, highly affected by a combination of climate change factors, and anthropogenic fires. Although most species of these ecosystems are fire tolerant, the mechanisms that lead to adaptive responses (metabolic reconfiguration) are unknown. In this context, the aim of this study was to characterize the primary metabolite composition of typical legume trees from these ecosystems, namely, Brachystegia boehmii (Miombo) and Colophospermum mopane (Mopane) subjected to different fire regimes. Fresh leaves from each species were collected in management units and landscapes across varied fire frequencies in the Niassa National Reserve (NNR) and Limpopo National Park (LNP) in Mozambique. Primary metabolites were extracted and analyzed with a well-established gas chromatography time-of-flight mass spectrometry metabolomics platform (GC-TOF-MS). In B. boehmii, 39 primary metabolites were identified from which seven amino acids, two organic acids and two sugars increased significantly, whereas in C. mopane, 41 primary metabolites were identified from which eight amino acids, one sugar and two organic acids significantly increased with increasing fire frequency. The observed changes in the pool of metabolites of $C$. mopane might be related to high glycolytic and tricarboxylic acid (TCA) rate, which provided increased levels of amino acids and energy yield. In B. boehmii, the high levels of amino acids might be due to inhibition of protein biosynthesis. The osmoprotectant and reactive oxygen species (ROS) scavenging properties of accumulated metabolites in parallel with a high-energy yield might support plants survival under fire stress.

Keywords: tree legumes, Miombo ecosystem, Mopane ecosystem, GC-TOF-MS, primary metabolome, fire tolerance 


\section{INTRODUCTION}

The tropical forest and savannas constitute one sixth of global terrestrial surface and more than a half of the African continent. The vegetation portions of these ecosystems possess about 53.000 plant species and correspond to $30 \%$ of global primary production. These ecosystems have a high ecological and socioeconomic impact being extremely important (i) in maintaining water, carbon and energy balance, (ii) as a source of high-quality wood, and (iii) and being highly used to treat animal and human diseases in local traditional medicine (White, 1983; Campbell et al., 1996; Ribeiro et al., 2010, 2012). The woodlands from southern Africa are composed mainly by strands of Miombo and Mopane (Allen et al., 2002; Bond et al., 2005; Neary et al., 2008). Miombo is dominated by the genera Brachystegia, Julbernardia, and Isoberlinia, while Mopane is nearly monospecific with the predominance of Colophospermum mopane. Miombo and Mopane ecosystems are frequently exposed to animal and human action and to adverse abiotic conditions, such as high temperature, ultraviolet irradiation, and drought. These factors are intimately associated with the occurrence of fires, whose regime can affect the structure and composition of the vegetation, thereby threatening the ecosystem's stability (Bohnert and Shen, 1998; Apel and Hirt, 2004; Shulaev et al., 2008).

Although much of the terrestrial vegetation is frequently affected by fire, the analysis of its impact in biological systems is poorly understood (Neary et al., 2008). Fire occurs at different frequencies and intensities that can result in a variety of ecological effects. When controlled, fire promotes dense and rapid regrowth, accelerating the natural cycle of primary production and respiration (Allen et al., 2002; Bond et al., 2005). In contrast, when not controlled, fire is associated with the increase of the superficial temperature and smoke concentration the reduction of humidity and water permeability due to the accumulation of hydrophobic elements in the soil, which in the last instance, determines seasonality distribution of nutrients (Solomon et al., 1994; Ledgards and Steelek, 2016). In addition, the morphology and physiology of B. boehmii and C. mopane are severely affected, e.g., aerial components of shrubs are destroyed and plant height and stem circumference are reduced (Henning, 1976, unpublished; Kennedy and Potgieter, 2003; Gandiwa and Kativu, 2009).

To cope with fire stress, $B$. boehmii and $C$. mopane have evolved morphology and physiology strategies. The roots and leaves of these plants are crucial organs that respond to changes in the surrounding environment that enables their survival under these adverse environmental conditions. These plants have high fin root densities (i.e., $20-120 \mathrm{~cm}$ depth) to facilitate quick water and nutrient uptake and transport (Smit and Rethman, 1998; Mantlana, 2002), and also have the ability to produce root suckers, which allow the shoots to grow faster than newly established seedlings (Luoga et al., 2004). Their leaves have leathery membranes that act as a buffer layer to avoid the heat and help reducing the rate of water loss through evapotranspiration. In addition, these leaves have a tendency to fold together, especially when the temperature exceeds $30^{\circ} \mathrm{C}$ (Madams, 1990).
Colophospermum mopane, in particular, contains crystals of calcium oxalate, which enhance wood resistance to fire through the production of a high $\mathrm{CO}_{2}$ concentration; a high concentration of $\mathrm{CO}_{2}$ acts as fire retardant by reducing the flame length (CICA, 1996). The resulting smoke is also composed by a diversity of volatile compounds, such as $\mathrm{O}_{3}, \mathrm{SO}_{2}$, and $\mathrm{NO}_{2}$, which promote the destruction of chlorophyll, inhibit the $\mathrm{K}^{+}$ channels that regulate guard cell functions (Shimazaki et al., 1984; Wellburn, 1985; Torsethaugen et al., 1999), reduce stomatal conductance, inhibit photosynthetic $\mathrm{O}_{2}$ evolution to the electron transport system, inactivate Calvin-Cycle enzymes, and reduce the main plant antioxidant enzymes (i.e., superoxide dismutase and glutathione reductase) (Tanaka et al., 2014).

Like other abiotic stresses, fire may cause osmotic stress that result in the increase of intracellular levels of reactive oxygen species (ROS). This process is characterized by dehydration and ion accumulation in the cytoplasm, inducing oxidative damage of proteins, nucleic acids, and lipids, leading to a loss of metabolic homeostasis (Bohnert and Shen, 1998; Apel and Hirt, 2004).

Some plant species tolerate environmental stresses through the activation of complex adaptative mechanisms. These include stress detection and activation of signal transduction mechanisms that ultimately lead to the production of antioxidants and accumulation of compatible solutes (e.g., sugars, amino acids, some amino acid derivatives, polyols, fructans and quaternary amino and sulfonium compounds) to acquire the new homeostatic state (Shulaev et al., 2008). Antioxidants prevent oxidative damage by "scavenging" ROS while compatible solutes alleviate the inhibitory effect of high ion concentration on enzyme activity, stabilize proteins and membranes, and also act as ROS “scavengers" (Solomon et al., 1994; Ledgards and Steelek, 2016).

Miombo and Mopane species, including B. boehmii and C. mopane, are widely reported to be fire tolerant and to have distinct reproductive and survival strategies in relation to fire, which might function as a potent biological filter (Stalmans et al., 2004; Shulaev et al., 2008). However, the metabolic mechanisms of resistance to this abiotic factor are unknown. Besides, there is few and incipient information regarding the primary metabolite composition of the species from both ecosystems (Chagonda et al., 1999; Ferreira et al., 2003) and, therefore, the novelty and pioneering aspect of this work.

Plants have high metabolite diversity with distinct physicochemical properties and multiple analytical platforms are often used for metabolite analysis, particularly those based on nuclear magnetic resonance (NMR) and mass spectrometry (MS). Because of its higher sensibility, MS methodologies are by far more used in metabolomics studies than NMR methodologies (Fernie et al., 2004); however, no single analytical platform is capable to analyze simultaneously the total metabolite pool present in complex mixtures, and therefore, metabolomics studies based in MS typically combine the use of complementary separation techniques, such as gas chromatography (GC) and liquid chromatography (LC) (Fernie et al., 2004; Jorge et al., 2016). In this study, a well-established gas chromatography coupled to time-of-flight mass spectrometry (GC-TOF-MS) platform was used to characterize the primary metabolome of 
B. boehmii and C. mopane, two woody leguminous species from the Miombo and Mopane vegetation, subjected to different fire regimes. Upon increasing fire frequency, a prominent variation of some primary metabolites was observed, which might reflect their antioxidant and osmoprotectant roles in adaptive mechanism responses of these species to fire.

\section{MATERIALS AND METHODS}

\section{Study Area and Sampling}

The study areas were located in the Niassa National Reserve (NNR) and Limpopo National Park (LNP). NNR is the most intact part of Miombo vegetation and represents one of the least disturbed areas of Africa's deciduous miombo woodlands, with a superficial extension of $42.000 \mathrm{Km}^{2}$. It is located in the Niassa Province, north of Mozambique, and it is limited in the north by Tanzania, and in the east and south by the Lugenda river (WWF, 2014). This reserve is characterized by humid tropical climate with an average annual rainfall between 600 and $1400 \mathrm{~mm}$ during the months of April and November, hottest average temperature of $30^{\circ} \mathrm{C}$, low fertile sandy-clayey soils, and according to data from MODerate Resolution Imaging Spectroradiometer (MODIS) sensor on board of NASA's Terra and Aqua Satellites, the burnt area in NNR corresponded to annual to tri-annual fires (SRN, 2005; Ribeiro et al., 2012). For management purposes, the reserve was divided in several management units (MUs), namely, R1-R6 and L1-L9. In this study, R4 and L3 were selected according to geographic proximity and differences in fire frequency: R4 with high fire frequency (HFF) (10-15 times in 12 years; the last fire took place 8 months before sampling) and L3 with low fire frequency (LFF) (3-5 times in 12 years; the last fire took place 7 months before sampling) (Cangela, 2014) (Figure 1 and Supplementary Table S1).

Limpopo National Park is part of the Mopane vegetation and constitutes the second most important vegetation area, with $10.000 \mathrm{Km}^{2}$ of superficial extension, located in the southern part of Gaza Province, south of Mozambique, on the eastern boundary of the Kruger National Park (Stalmans et al., 2004; MAE, 2005). LNP is characterized by subtropical climate with an average annual rainfall between 360 and $500 \mathrm{~mm}$ during the months of March and August, hottest average temperature of $40^{\circ} \mathrm{C}$, limestone and rocky soils, and according to data from MODIS sensor on board of NASA's Terra and Aqua Satellites, the burnt area in LPN showed a quasi-biannual pattern, with highest burnt areas occurring in 2004, 2006, and 2008 (MAE, 2005; Govender et al., 2015).

The park was divided in landscapes, namely, S1-S12. In this study, S2, S3 from Calcrete area, and S6, S7 from Lebombo north area, were selected according to geographic location and differences in fire frequency: S2 and S6 with LFF (2-3 times in 10 years; in S2, the last fire took place 10 months before sampling whereas in $\mathrm{S} 6$ the last fire took place 33 months before sampling), S3 and S7 with HFF (8-10 times in 10 years; the last fire took place 8 months before sampling and 20 months before sampling, respectively). All of them have burnt at least twice between 2010 and 2013 (Govender et al., 2015) (Figure 2 and Supplementary Table S2).

Due to the dynamics of Miombo and Mopane ecosystems (Figures 1, 2), areas without fire incidence are not available; actually, low fire frequencies are indeed the "positive controls" on the ecology of these ecosystems (Ribeiro et al., 2017). Samples were obtained using the Stratified Random sampling, where the population was first divided into strata according to the fire frequency. Then, in each site and MU, four linear transects (each with $160 \mathrm{~m}$ and four plots, distance between plots was $40 \mathrm{~m}$ ) were delineated (replicas). In the center of each plot, six young undamaged leaves were collected per plant. However, due to the remoteness of the areas under study, fewer sites were accessed.

Samples of B. boehmii in NNR were collected between June and July 2012 (Supplementary Table S1) where average temperature of sampling sites was $22^{\circ} \mathrm{C}$ and rainfall $1.5 \mathrm{~mm}$. Samples of C. mopane in LNP were collected in June 2014 (Supplementary Table S2), where the average temperature of collecting sites was $17.5^{\circ} \mathrm{C}$ and raifall $73.25 \mathrm{~mm}$. For each sampling point, the environmental variables and fire events were recorded (Supplementary Tables S1, S2). Leaves were stored in silica gel rubin (Fluka) for about 1 week (the time of the trip from the field to the lab) and then frozen in liquid nitrogen and stored at $-80^{\circ} \mathrm{C}$ at the Biotecnology Center Lab of the Eduardo Mondlane University until lyophilization and subsquent metabolite analysis.

\section{Primary Metabolite Extraction, Derivatization and GC-TOF-MS Analysis}

Primary metabolites were extracted following a previously described protocol (Lisec et al., 2006). Briefly, lyophilized leaves of $20 \mathrm{~B}$. boehmii plants and $40 \mathrm{C}$. mopane plants were homogenized separately using a mortar and pestle filled with liquid nitrogen. Approximately $20 \mathrm{mg}$ (DW, dry weight) were weighed into $2.0 \mathrm{~mL}$ safe-lock polypropylene microfuge tubes (Eppendorf, Hamburg, Germany) and primary metabolites were extracted using $1400 \mu \mathrm{L}$ of methanol (100\%) containing ribitol $\left(0.2 \mathrm{mg} \mathrm{mL} \mathrm{mL}^{-1}\right.$ in water) as internal standard. The mixture was incubated on a shaker at $70^{\circ} \mathrm{C}$ for $15 \mathrm{~min}$ (Thermomixer C, Eppendorf, Hamburg, Germany) and centrifuged for $10 \mathrm{~min}$ at $11000 \times g$ (Centrifuge 5430, Eppendorf, Hamburg, Germany) at $25^{\circ} \mathrm{C}$. The supernatant was transferred to a glass vial (Schott GL14, Mainz, Germany) and $750 \mu \mathrm{L}$ of chloroform were added followed by $375 \mu \mathrm{L}$ of distilled water. The resulting mixture was vortex-mixed for $15 \mathrm{~s}$, and centrifuged for $15 \mathrm{~min}$ at $2200 \times g$ (Centrifuge 5810R, Eppendorf, Hamburg, Germany). Finally, $150 \mu \mathrm{L}$ of the upper phase (polar phase) of each sample were transferred to a new $1.5 \mathrm{~mL}$ microfuge tube (Eppendorf, Hamburg, Germany) and dried down with a vacuum concentrator (Concentrator CentriVap, Labconco, Kansas City, MO, United States) for 3 h. Biological variations were controlled by analyzing quality control (QC) standards by fatty acid methyl esters (FAMES) internal standard markers and a QC standard solution of 41 pure reference compounds (i.e., the most detected and abundant metabolites) throughout the analysis. The final dried extracts were filled with argon gas 

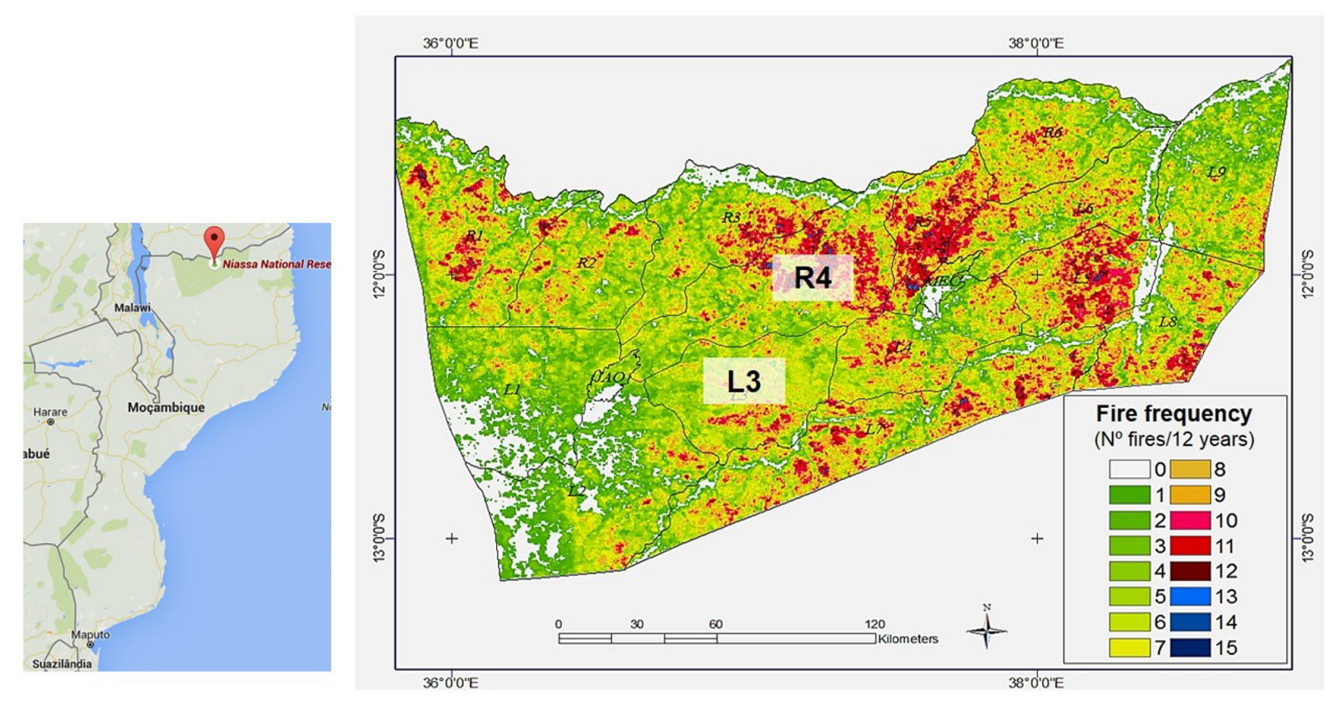

FIGURE 1 | Niassa National Reserve (NNR) fire areas map: L3 (LFF) and R4 (HFF) corresponds to B. boehmii sampling areas (Cangela, 2014).

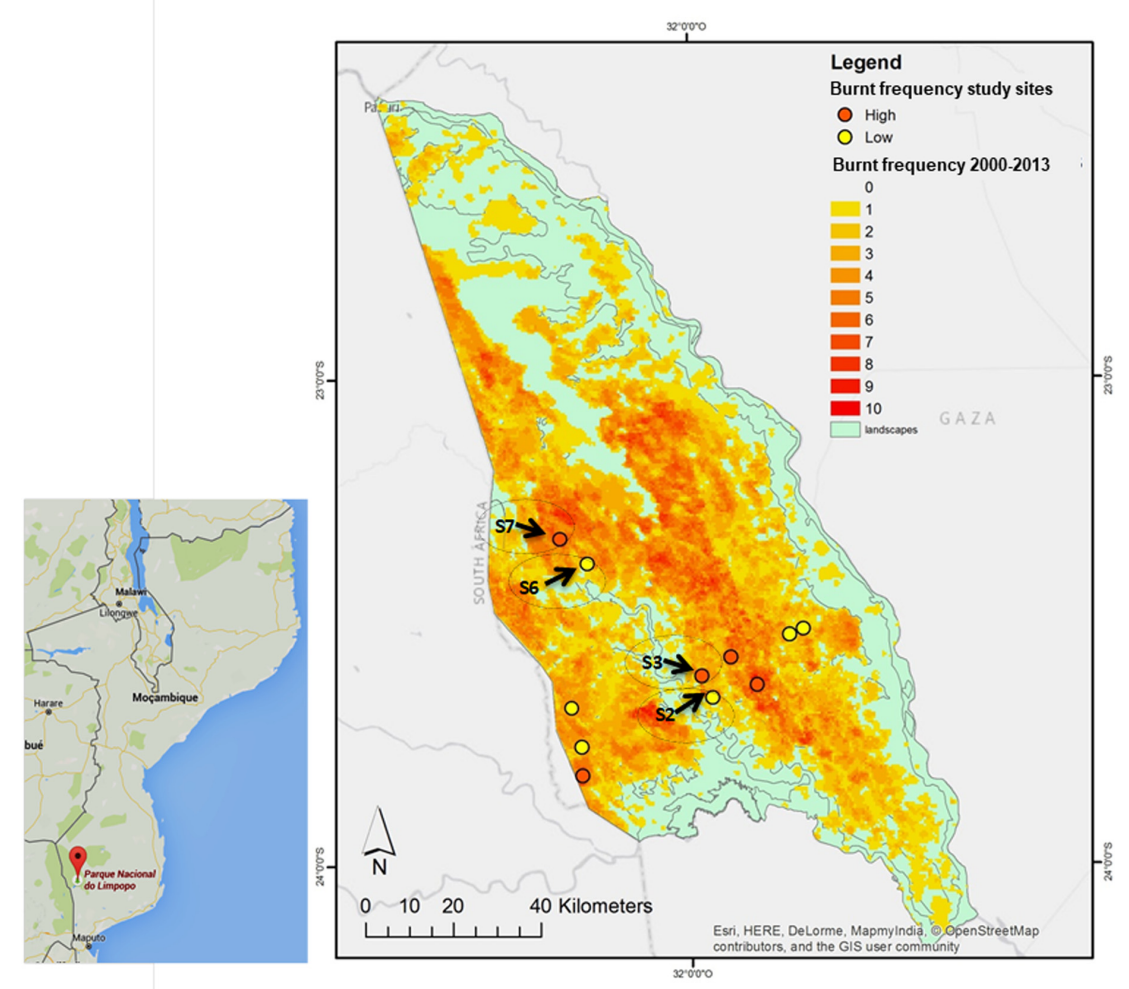

FIGURE 2 | Limpopo National Reserve (LNR) fire areas map: S2, S6 (LFF) S3, S7 (HFF) corresponds to C. mopane sampling areas (Navashni et al., 2015).

to avoid oxidation and degradation of extracted metabolites by reactions with atmospheric air components, and stored at $-80^{\circ} \mathrm{C}$ prior to derivatization and GC-TOF-MS analysis. Extracted primary metabolites were derivatized and analyzed with gas chromatography coupled to time-of-flight mass spectrometry (GC-TOF-MS) according to a well-established GC-TOF-MS protocol (Lisec et al., 2006). The system consisted of a gas chromatograph (6890N Plus, Agilent Technologies, Böblingen, 
Germany) coupled to a TOF-MS (Pegasus III TOF MS system, LECO, Mönchengladbach, Germany), in which $1 \mu \mathrm{L}$ of sample were injected (Supplementary Files S1, S2).

\section{Data Analysis and Statistics}

After GC-TOF-MS analysis, the obtained files (cdf. format) with each chromatogram and mass spectra for each sample were analyzed using AMDIS (Automated Mass Spectral Deconvolution and Identification System) software (v 2.71). Primary metabolites were annotated using the TagFinder software, matching mass spectral and retention time index to the reference collection of authenticated standard substances from the Golm Metabolome Database (Luedemann et al., 2008). The relative abundance of primary metabolites was normalized dividing the corresponding values by the dry weight (DW) of the samples and the signal intensity of the internal standard (ribitol) (Supplementary Files S1, S2).

Significant differences between LFF and HFF samples were estimated with Student $t$-test $(p<0.05)$ using the R-software (R Core Team, 2016) (Supplementary Tables S1-S5). The $p$-values were corrected for multiple comparisons using the Benjamini-Hochberg False Discovery Rate (FDR) correction (Supplementary File S3). Principle Component Analysis (PCA), Partial Least Squares Discriminant Analysis (PLS-DA) and Heatmap plots were obtained in the $\mathrm{R}$ software using the packages: pcamethods (Stacklies et al., 2007), mixOmics (Le Cao et al., 2016) and pheatmap (Raivo, 2015).

\section{RESULTS}

\section{Primary Metabolite Profiling of B. boehmii}

GC-TOF-MS analysis allowed the identification of 39 primary metabolites in B. boehmii, namely, 14 amino acids, ten sugars, nine organic acids, four polyols, and two polyamines, whose relative abundance varied prominently between high fire frequency (HFF) and low fire frequency (LFF) samples (Figures 3, 4 and Supplementary Table S3). Increasing fire frequency caused a significant $(p<0.05)$ increase of the aminoacids glycine (Gly), alanine (Ala), valine (Val), glutamate (Glu), $\gamma$-amino butyric acid (GABA), isoleucine (IIe) and threonine (Thr). In respect to sugars, a significant increase was observed for galactose (Gal) with increasing fire frequency, but in general, most sugars remained unchanged. The sugar alcohol glycerol was observed to significantly $(p<0.05)$ increase with increasing fire frequency. Just over a third of organic acids significantly increased with increasing fire frequency, namely threonate and glycerate.

Principle component analysis analysis allowed for the identification of patterns between the LFF and the HFF B. boehmii samples. The first two principal components (PC1 and PC2) accounted for $57.09 \%$ of the total variance and revealed a separation between the two group samples (Figure 6A). To gain further insights on the fire-responsive metabolites that discriminate as much as possible the group samples, we have then applied a validated supervised PLS-DA model (Figure 7A). Our

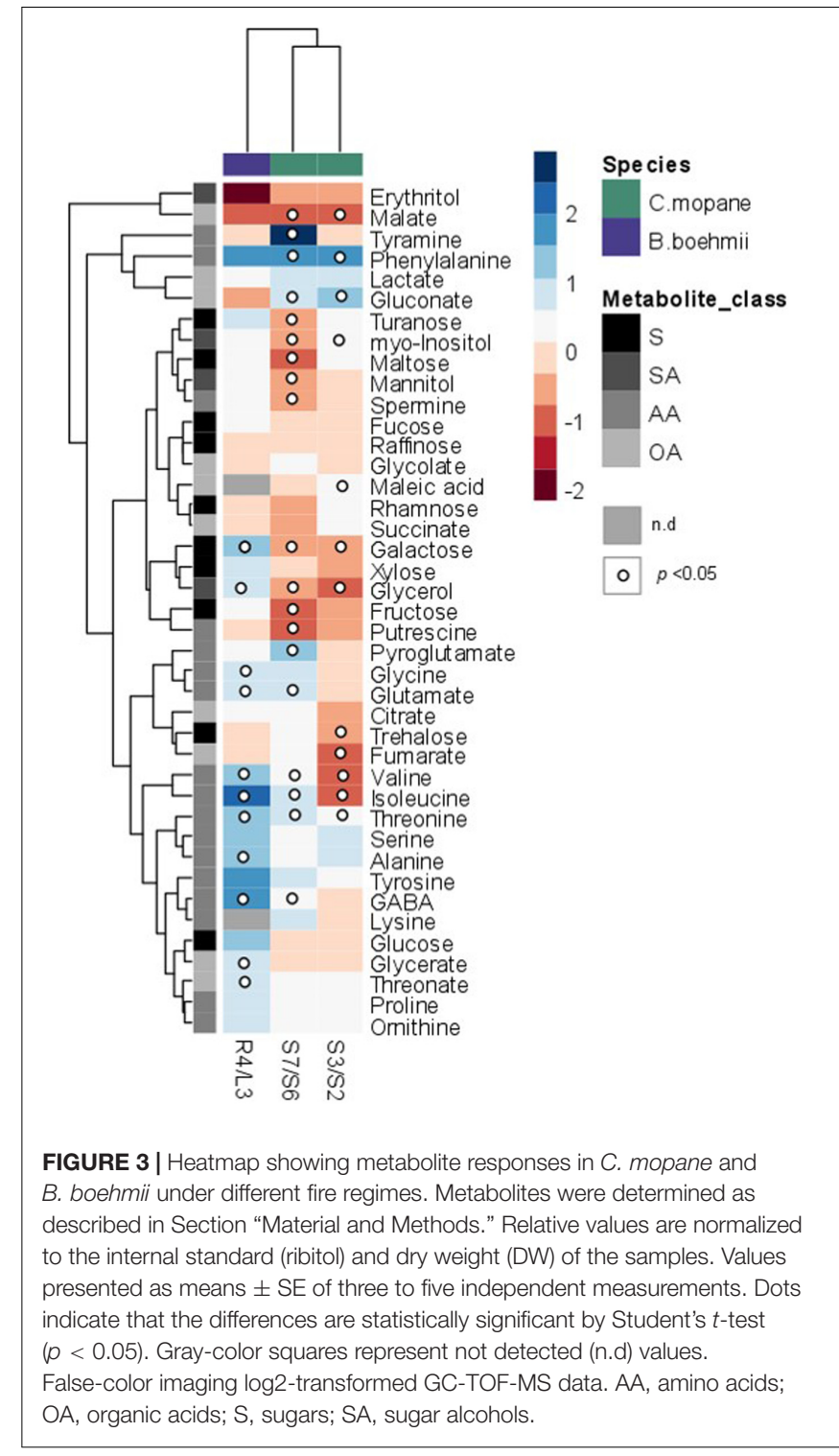

PLS-DA models were validated based on the criterion of lowest classification error rate using the leave-one-out cross-validation embedded in the R package "mixOmics" (Supplementary File S4). PLS-DA analysis revealed to be effective in separating the LLF samples from the HFF samples (Figure 7A) and we were able to identify that those metabolites that significantly increased $(p<0.05)$ in HFF were also responsible for the clustered of these group of samples (Figure 7A).

An author metabolite pathway map of B. boehmii (Figure 4) was generated in order to predict sites of metabolic regulation. The metabolite pathway map shows that HFF results in the accumulation of many sugars, which may reveal low glycolysis ratio, and low amino acids precursors from glycolysis (glucose-6phosphate (Glc-6-P) and pyruvate (Pyr)) and TCA [oxaloacetate (OAA) and 2-oxo-glutarate (2OG)], however, the vast majority of amino acids accumulated, which may be due to other factors aside from central metabolism. 


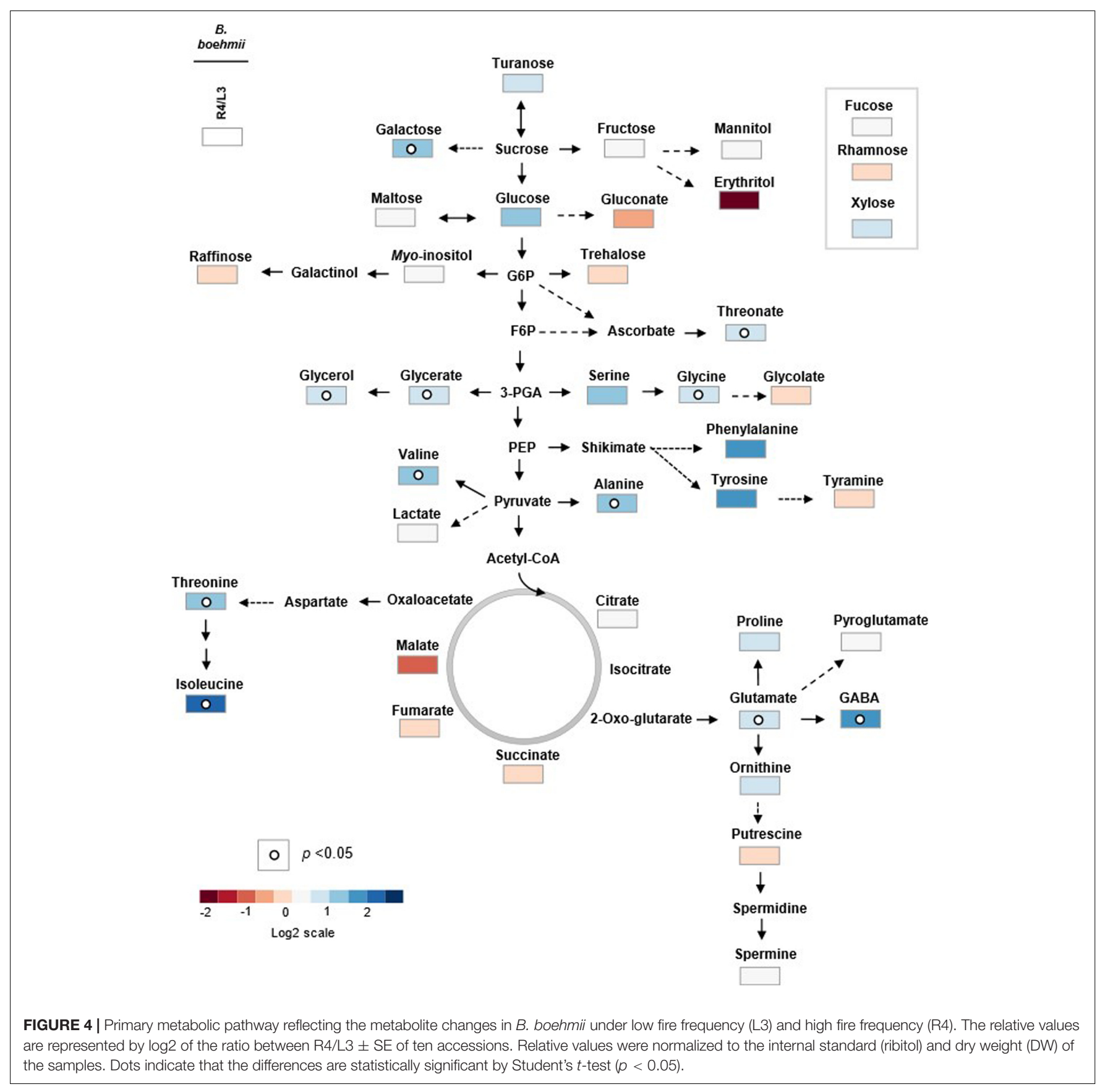

\section{Primary Metabolite Profiling of C. mopane}

In C. mopane 41 primary metabolites were identified, namely 15 amino acids, ten sugars, ten organic acids, four polyols and two polyamines (Figures 3, 5 and Supplementary Tables S4, S5), whose relative abundance varied notably between HFF and LFF samples. Comparing the metabolite profiles of trees from Lebombo north landscapes S6-LFF versus S7-HFF (Figures 3, 5 and Supplementary Table S4), the vast majority of amino acids levels increased significantly $(p<0.05)$ with the increasing of fire frequency, particularly Phe (up to threefold) and tyramine (up to sevenfold). On the other hand, HFF resulted in the decrease of the majority of sugars, but only fructose (Fru), Gal, maltose and turanose decreased significantly. More than a half of organic acids showed a tendancy to accumulate. Almost all sugar alcohols, namely, glycerol, mannitol and myo-inositol as well as the polyamines putrescine (Put) and spermine (Spm) were shown to decrease significantly.

For the metabolite profiles between trees from Calcrete landscapes S2-LFF and S3-HFF (Figures 3, 5 and Supplementary Table S5) only a couple of the amino acids significantly increased with increasing fire frequency, namely, Thr and Phe which 


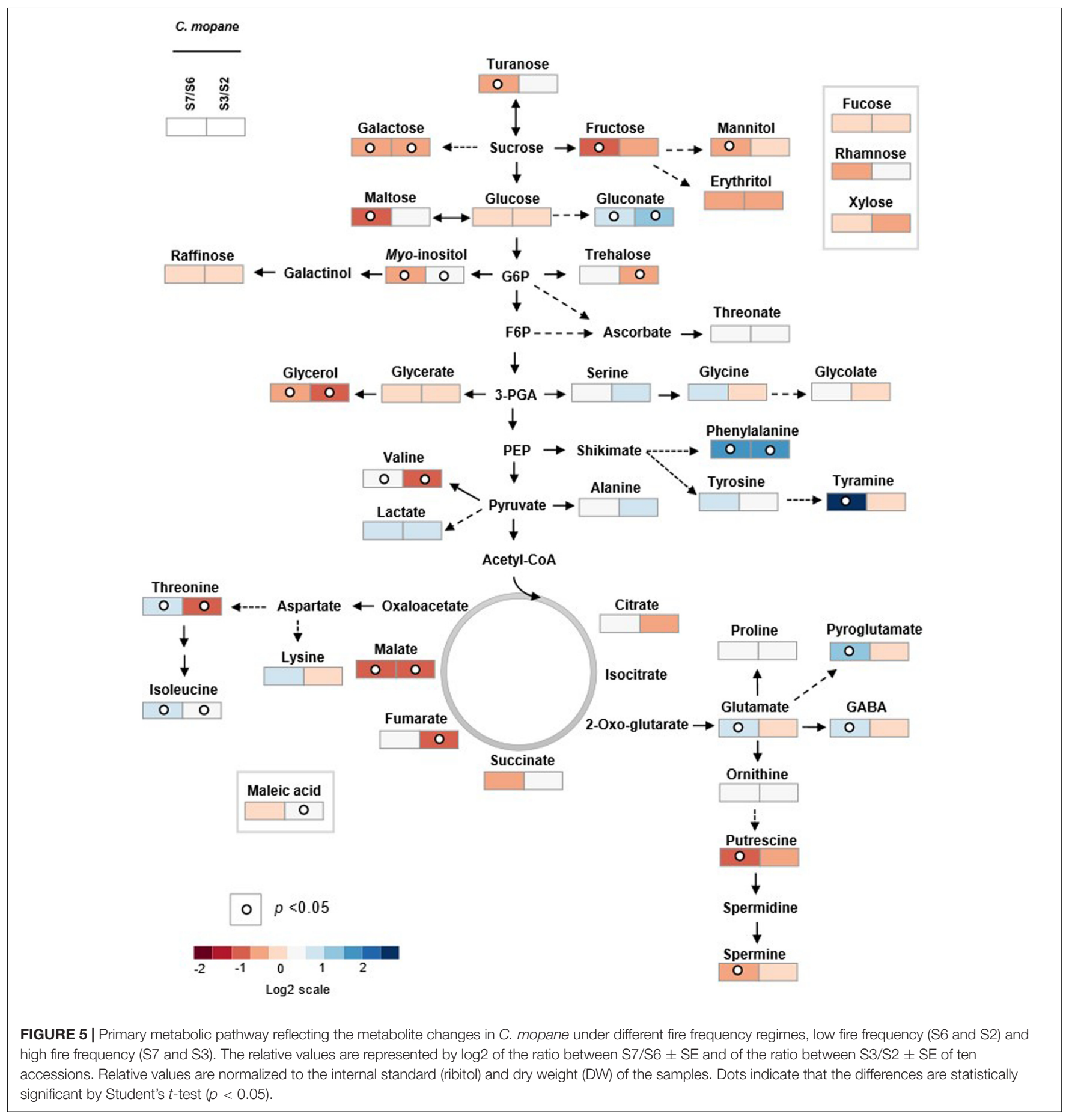

accumulated up to threefold. On the other hand, only two amino acids, Ile and Val, decreased significantly $(p<0.05)$. Among sugars and sugar alchohols, the relative abundance of Gal, trehalose (Tre) and glycerol decreased significantly with increasing fire frequency whereas myo-inositol increased. Only a few organic acids increased significantly with the fire frequency, namely, malate and gluconate. On the other hand, the levels of the tricarboxilic acid (TCA)-cycle intermediates fumarate and malate decreased significantly.
The PCA analysis of the C. mopane samples based on the first two principal components that accounted for $37.12 \%$ of the total variance also revealed a separation between the LFF and the HFF group samples (Figure 6B). In additon, the PLS-DA analysis revealed to be effective in separating the LLF samples of the S6 MU from the HFF of the S7 MU as well as the LFF samples of the S2 MU from the HFF of the S3 MU (Figure 7B). Moreover, the samples from the S6 MU were clearly separated from those of the different MUs. Regarding the loading plots, 

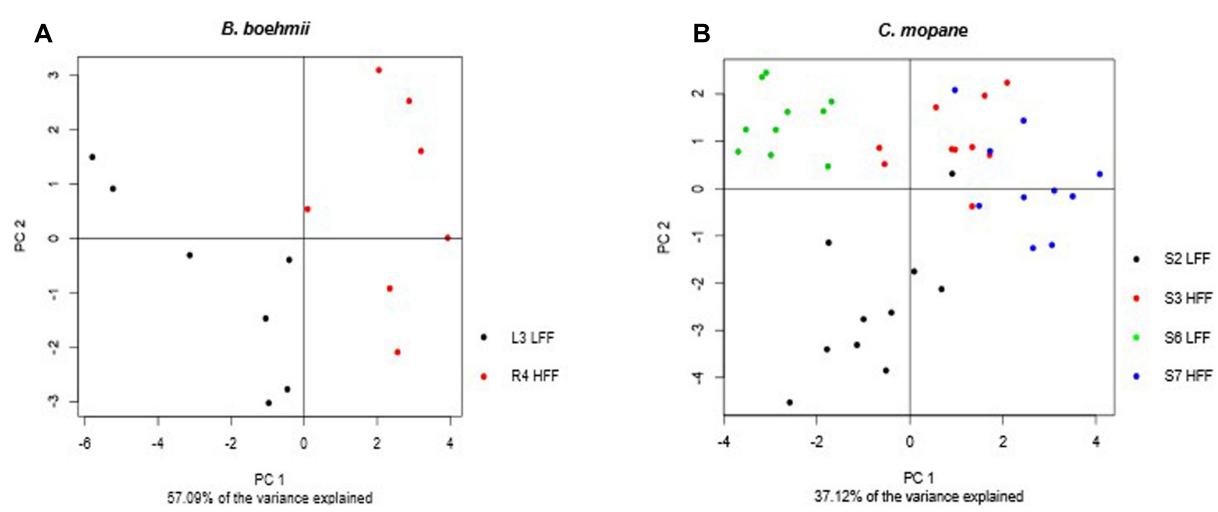

FIGURE 6 | Principal component analysis (PCA) score plots of metabolic profiles for (A) B. boehmii under low fire frequency (L3) and high fire frequency (R4) and (B) C. mopane under different fire frequency regimes, low fire frequency (S6 and S2) and high fire frequency (S7 and S3).
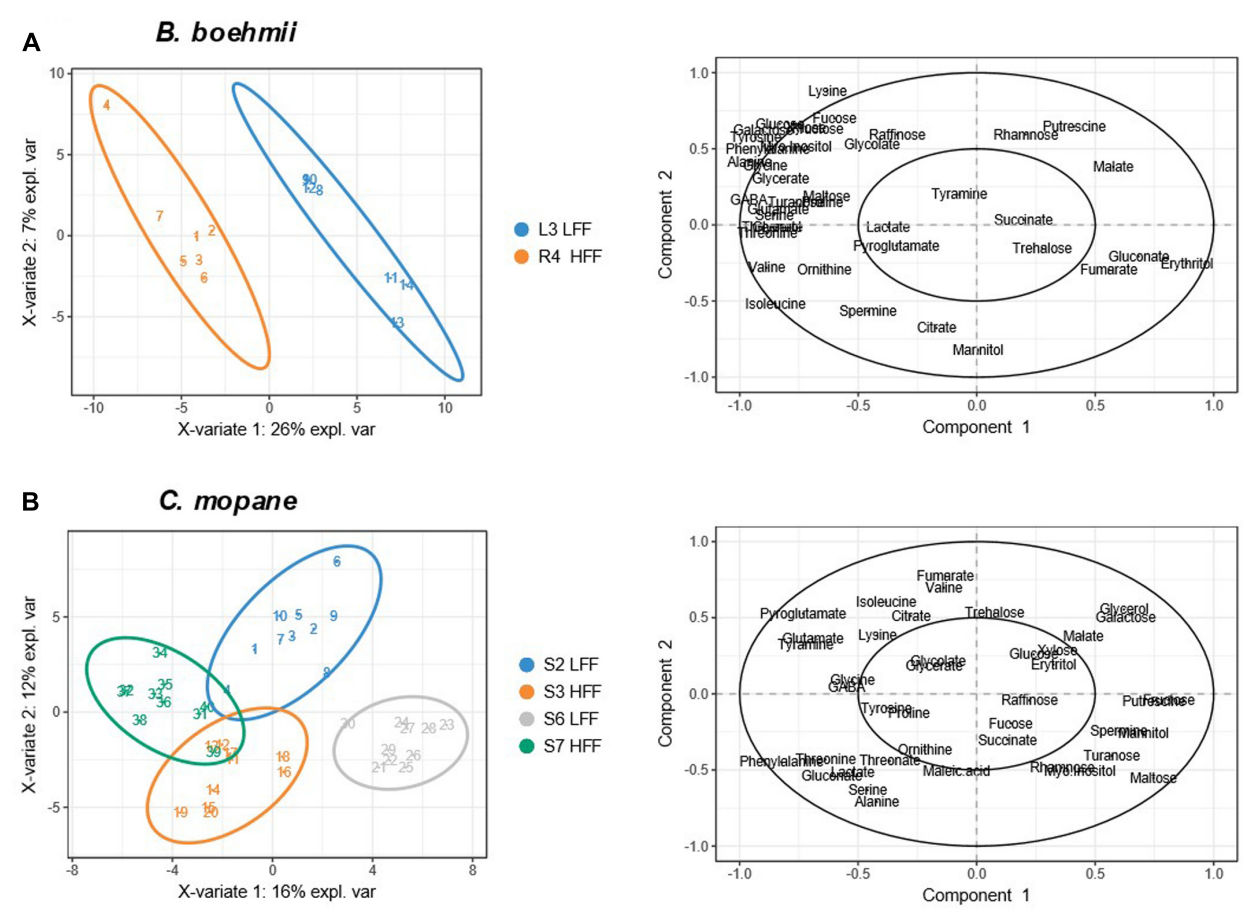

FIGURE 7 | Partial Least Square Discrimination (PLS-DA) score and loading plots for (A) B. boehmii under low fire frequency (L3) and high fire frequency (R4) and (B) C. mopane under different fire frequency regimes, low fire frequency (S6 and S2) and high fire frequency (S7 and S3).

it was observed that while S6-LFF samples are separated from S7-HFF samples by the vertical axis ( $y$-axis), the separation of S2LFF samples from S3-HFF is visble by the horizontal axis ( $x$-axis) (Figure 7B). Following this, the metabolites that significantly increased $(p<0.05)$ under HFF were clustered in the negative side of the $y$ - and $x$-axis, respectively. On the other hand, the metabolites significantly decrease $(p<0.05)$ in the HFF samples were clustered in the positive side of the $y$-and $x$-axis.

To predict sites of metabolic regulation an author metabolite pathway map of C. mopane was generated (Figure 5). The map shows general decreasing of sugar concentration, which may show high glycolysis ratio, and probably related with the increasing of some TCA-cyle intermediate concentrations (malate, succinate in S2 and S3 landscapes, citrate, fumarate in S6 and S7 landscapes). In the context of HFF, it is also notable that some of glycolysis (Glc-6-P) and TCA (OAA and 2-OG) intermediates were probably the precursors of the biosynthesis of the vast majority of accumulated amino acids.

\section{DISCUSSION}

Environmental stresses lead to a loss of metabolic homeostasis in plants, which can be characterized by an imbalance between 
the production of ROS and antioxidant molecules (Mittler, 2006). The excess of ROS causes oxidative damage in biomolecules, such as, proteins, nucleic acids, and lipids (Manderscheid et al., 1992; Martinelli et al., 2007). According to our data, HFF increases the relative abundance of amino acids in both B. boehmii and C. mopane of the Lebombo north area and some amino acids of the Calcrete area. This profile can be associated with the adaptation of these species to stress caused by fire. Plants under abiotic stress accumulate amino acids in their cytoplasm, that play an important osmoprotectant role by helping plant cells to maintain their cellular turgor as well as to stabilize cellular membranes thereby preventing nucleic acid, protein, and lipid degradation (Mittler, 2006; Martinelli et al., 2007). Furthermore, amino acids can synergistically interact with phenols to form redox systems to "scavenge" ROS, enhancing the process of stress tolerance (Bolouri-Moghaddam et al., 2010). The accumulation of the non-protein amino acid GABA is probably related to signaling and regulation of different mechanisms of stress response, such as carbon and nitrogen balance, osmotic potential, ROS "scavenging" and $\mathrm{pH}$ regulation (Kinnersley and Turano, 2000; Lancien and Roberts, 2006). On the other hand, the accumulation of proteinogenic amino acids can reveal the inhibitory effect of heat in protein synthesis. Furthermore, the higher relative abundance of Val is probably linked to fire tolerance, as it has been reported to be strongly related to heat stress, but the specific mechanism is still unknown (Yu et al., 2012).

In respect to $B$. boehmii, the increase in fire frequency led to a general increase of molecules with osmoprotectant properties, such as sugars, and a decrease of TCA-cycle intermediates, which suggests the occurrence of low glycolysis and energy production rates, namely, ATP, $\mathrm{FADH}_{2}$ and NADH (Dias et al., 2015). Like amino acids, sugars can act as osmolytes, that contribute to maintain the cellular turgor, membrane stabilization and prevent protein degradation (Dias et al., 2015). The opposite was observed in C. mopane, except for maltose and myo-inositol. The decrease in the relative abundance of sugars was more prominent in trees from Libombo north than from Calcrete, but in both cases, were inversely related to the relative abundances of TCA-cycle intermediates, suggesting a parallel increase of the glycolysis and energy production rates (e.g., ATP, $\mathrm{FADH}_{2}$ and $\mathrm{NADH}$ ) with increasing fire frequency (Dias et al., 2015). The higher amino acid levels can be a reaction to fire stress and similar profiles were observed in Acacia ampliceps Maslin exposed to salt stress (Sanchez et al., 2008; Theerawitaya et al., 2015), suggesting that the osmoprotective role of amino acids is the common response of many plant species to abiotic stress.

Polyols and organic acids are another type of molecules involved in osmoprotection and maintenance of metabolic processes under abiotic stress (Sanchez et al., 2008; Xu et al., 2008; Theerawitaya et al., 2015). The accumulation of glycerol in B. boehmii and myo-inositol in C. mopane might be related to the scavenging of hydroxyl radicals (Xu et al., 2008) while the accumulation of threonine might be linked to the maintenance of ionic balance at the membrane level (Bolouri-Moghaddam et al., 2010).

The changes in the pool of TCA-cycle intermediates along with the decrease of sugars in C. mopane might be related with an increased rate of glycolysis for use in the TCA cycle, which in turn provides precursors for other reactions such as the biosynthesis of amino and organic acids. In addition, it also provides chemical energy in the form of adenosine triphosphate (ATP) and nicotinamide adenine dinucleotide hydrogen (NADH) which might be needed to support plant survival during fire stress. The opposite behavior was observed in B. boehmii, where the decreased pool of TCA-cycle intermediates agreed with an increase of several sugars; this fact points to a low glycolytic rate as well as ATP and NADH yield. However, while most of the accumulated amino acids might not result from reactions of the glycolytic pathway or TCAcycle intermediates, it might be due to the inhibition or depletion of protein biosynthesis. The accumulation of amino acids and sugars, well-known for their osmoprotectant role (Dias et al., 2015), might be an indicative that B. boehmii and C. mopane have a stress memory that supports survival under fire conditions or allows crosstalk between different environmental stimuli related to fire [e.g., high temperature $\left(30-40^{\circ} \mathrm{C}\right.$ ); low rainfall (NNR: $600-1400 \mathrm{~mm}$; LNP: $360-$ $500 \mathrm{~mm}$ ); low fertile soil (NNR: sandy; LNP: limestone and rocky)], leading to a transcriptional/somatic stress memory (phenotypic plasticity) (Bradshaw et al., 2011; Ding et al., 2012; Feng et al., 2016). In fact, thermo-tolerance in plants related to heat-stress memory is actively maintained due to the temporary activation of heat-inducible genes (memory genes) after a priming heat stress (Charng et al., 2006; Feng et al., 2016).

The different primary metabolite profile between $B$. boehmii and $C$. mopane suggests distinct response mechanisms to fire. On one hand, the accumulation of sugars and amino acids in B. boehmii is probably related to osmoprotection, "scavenging" of ROS and $\mathrm{pH}$ regulation. On the other hand, the accumulation of amino acids and reduction of sugars in C. mopane is probably related to osmoprotection processes and energy production, respectively.

The differences between the primary metabolites profiles of C. mopane plants from the two sites of LNP might be related to intraspecific genetic polymorphism or to ecologic factors, such as geomorphologic conditions and composition of woody vegetation. Indeed, the soil type determines the composition of woody vegetation of LNP. While in the rocky soils of Libombo north, Combretum apiculatum (Sond) was the only sub-dominant woody species observed, in calcareous soils from Calcrete, a variety of sub-dominant woody species, such as Eucleia ssp, Grewia spp, Dalbergia melanoxylon (Guill \& Perr) occur, suggesting that the dominant mopane plants from Calcrete are subjected to a higher competition with woody vegetation than mopane plants from Libombo north (Stalmans et al., 2004; Govender et al., 2015). Overall, these factors might influence the response of C. mopane to stress, thus explaining the differences in the metabolite profiles. 
In summary, the primary metabolite profiles of $B$. boehmii and $C$. mopane are different, except for the amino acids Ala, Ser, Thr, Phe, GABA, glutamate (Glu), Gly, Ile, Pro, tyrosine (Tyr) and Val, which probably represent a convergent response of both species to fire. That convergent response may reflect the fact that both species belong to the same family and probably share common genes with the same expression pattern and regulation of metabolic pathways of amino acid metabolism in environmental stress conditions.

The use of a well-established GC-TOF-MS metabolite profiling approach to measure known primary metabolites (e.g., sugars, amino and organic acids) has proven to be a powerful analytical tool to improve our understanding of how and to which extent $B$. boehmii and $C$. mopane metabolism readjusts to fire exposure in the Miombo and Mopane ecosystems, respectively. The observed accumulation of amino acids and sugars in B. boehmii and C. mopane might be related to fire tolerance mechanisms in these species, such as osmoprotection, "scavenging" of ROS, and high rates of energy production.

This study represents a pioneering approach to profile the primary metabolome of $B$. boehmii and $C$. mopane, and constitutes an important starting point to further investigate biochemical markers of thermal stress tolerance in other African leguminous species from the Miombo and Mopane ecosystems. To complement this study, the characterization of the secondary metabolome of B. boehmii and C. mopane with LC-MS/MS approaches is being carried out. Preliminary results indicate that these plants contain added-value phenolic compounds with antibacterial and antioxidant properties, which levels have shown to increase with fire frequency.

\section{AUTHOR CONTRIBUTIONS}

$\mathrm{NR}, \mathrm{AR}-\mathrm{B}$, and CA conceived and designed the project. IM collected the samples. JD and TJ were responsible for all plant

\section{REFERENCES}

Allen, C. D., Savage, M., Falk, D., Suckling, K. F., Thomas, W., Schulke, T., et al. (2002). Ecological restoration of southwestern ponderosa pine ecosystems: a broad perspective. Ecol. Appl. 12, 1418-1433. doi: 10.1890/1051-0761(2002) 012[1418:EROSPP]2.0.CO;2

Apel, K., and Hirt, H. (2004). Reactive oxygen species: metabolism, oxidative stress, and signal transduction. Annu. Rev. Plant Biol. 55, 373-399. doi: 10.1146/ annurev.arplant.55.031903.141701

Bohnert, H. J., and Shen, B. (1998). Transformation and compatible solutes. Sci. Hortic. 78, 237-260. doi: 10.1016/S0304-4238(98)00195-2

Bolouri-Moghaddam, M., Le, R., Xiang, L., Rolland, F., and Ende, V. (2010). Sugar signalling and antioxidant network connections in plant cells. FEBS J. 277, 2022-2037. doi: 10.1111/j.1742-4658.2010.07633.x

Bond, W. J., Woodward, F. I., and Midgley, G. F. (2005). The global distribution of ecosystems in a world without fire. New Phytol. 165, 525-538. doi: 10.1111/j. 1469-8137.2004.01252.x

Bradshaw, S. D., Dixon, K. W., Hopper, S. D., Lambers, H., and Turner, S. R. (2011). Little evidence for fire-adapted plant traits in Mediterranean climate regions. Trends Plant Sci. 16, 69-76. doi: 10.1016/j.tplants.2010. 10.007 metabolomics workflows. JD, TJ, and CA analyzed the data. CA and AR-B contributed with reagents, materials, and analysis tools. JD, TJ, IM, AR-B, and CA wrote the paper.

\section{FUNDING}

This work was supported by the Ministry of Science and Technology and Higher Education of Mozambique, by the Portuguese Cooperation via Camões Institute of Cooperation and Language, by national funds from Fundação para a Ciência e a Tecnologia (FCT) through the FCT Investigator Program (contract IF/00376/2012/CP0165/CT0003 CA), and by the ITQB NOVA R\&D unit GreenIT 'Bioresources for Sustainability' (UID/Multi/04551/2013). TJ further acknowledges the Ph.D. fellowship funded by FCT (PD/BD/113475/2015) and the ITQB NOVA International Ph.D. Program 'Plants for Life' (PD/00035/2013).

\section{ACKNOWLEDGMENTS}

CA gratefully acknowledges Dr. Alisdair R. Fernie, Central Metabolism group at the Max Planck Institute of Molecular Plant Physiology (MPIMP) in Potsdam-Golm (Germany) for kindly providing the access to a GC-TOF-MS metabolite profiling platform to analyze the $B$. boehmii and C. mopane samples.

\section{SUPPLEMENTARY MATERIAL}

The Supplementary Material for this article can be found online at: https://www.frontiersin.org/articles/10.3389/fpls.2017.02130/ full\#supplementary-material

Campbell, B., Frost, P., and Byron, N. (1996). "Miombo woodlands and their use: overview and key issues," in The Miombo in Transition: Woodlands and Welfare in Africa, ed. B. Campbell (Bogor: CIFOR), 1-5.

Cangela, A. (2014). Caracterização e Mapeamento do Regime de Queimadas na Reserva Nacional de Niassa. Master thesis, Universidade Eduardo Mondlane.

Chagonda, L., Makanda, C., and Chalchat, J. (1999). Essential oils of four wild and semi-wild plants from Zimbabwe: Colophospermum mopane (Kirk ex Benth.) Kirk ex Leonard, Helichrysum splendidum (Thumb.) Less, Myrothamnus flabellifolius (Welw.) and Tagetes minuta L. J. Essent. Oil Res. 11, 573-578. doi: 10.1080/10412905.1999.9701217

Charng, Y., Liu, H., Liu, N., Hsu, F., and Ko, S. (2006). Arabidopsis Hsa32, a novel heat shock protein, is essential for acquired thermotolerance during long recovery after acclimation. Plant Physiol. 140, 1297-1305. doi: 10.1104/pp.105. 074898

CICA (1996). Africa's Shrinking Savannas. Available at: http://www.ibiblio.org/ london/agriculture/forums/sustainable-agriculture2/msg00402.html

Dias, D., Hill, C., Jayasinghea, N., Atienoc, J., Suttonc, T., and Roessner, U. (2015). Quantitative profiling of polar primary metabolites of two chickpea cultivars with contrasting responses to salinity. J. Chromatogr. B 1000, 1-13. doi: 10.1016/ j.jchromb.2015.07.002 
Ding, Y., Fromm, M., and Avramova, Z. (2012). Multiple exposures to drought 'train' transcriptional responses in Arabidopsis. Nat. Commun. 13:740. doi: 10.1038/ncomms1732

Feng, X. J., Lia, J. R., Qia, S. L., Lina, Q. F., Jin, J. B., and Hua, X. J. (2016). Light affects salt stress-induced transcriptional memory of P5CS1 in Arabidopsis. Plant Biol. 51, E8335-E8343. doi: 10.1073/pnas.1610670114

Fernie, A., Trethewey, R., Krotzky, A., and Willmitzer, L. (2004). Metabolite profiling: from diagnostics to systems biology. Nat. Rev. Mol. Cell Biol. 5, 763-769. doi: 10.1038/nrm1451

Ferreira, D., Marais, J., and Slade, D. (2003). Phytochemistry of the mopane, Colophospermum mopane. Phytochemistry 64, 31-51. doi: 10.1016/S00319422(03)00152-3

Gandiwa, E., and Kativu, S. (2009). Influence of fire frequency on Colophospermum mopane and Combretum apiculatum woodland structure and composition in northern Gonarezhou National Park, Zimbabwe. Koedoe 51:13. doi: 10.4102/ koedoe.v51i1.685

Govender, N., Ribeiro, N., Macandza, V., and Ruecker, G. (2015). Comparing Two Fire Management Strategies in the GLTP: Creating the Foundations for a Fire Management System in the LNP. Limpopo: Kruger National Park.

Jorge, T. F., Rodrigues, J. A., Caldana, C., Schmidt, R., van Dongen, J. T., ThomasOates, J., et al. (2016). Mass spectrometry-based plant metabolomics: metabolite responses to abiotic stress. Mass Spectrom. Rev. 35, 620-649. doi: 10.1002/mas. 21449

Kennedy, A. D., and Potgieter, A. L. F. (2003). Fire season affects size and architecture of Colophospermum mopane in southern African savannas. Plant Ecol. 167, 179-192. doi: 10.1023/A:1023964815201

Kinnersley, A., and Turano, F. (2000). Gamma aminobutyric acid (GABA) and plant responses to stress. Crit. Rev. Plant Sci. 19, 479-509. doi: 10.1080/ 07352680091139277

Lancien, M., and Roberts, M. R. (2006). Regulation of Arabidopsis thaliana 14-3-3 gene expression by GABA. Plant Cell Environ. 29, 1430-1436. doi: 10.1111/j. 1365-3040.2006.01526.x

Le Cao, K. A., Rohart, F., Gonzalez, I., Dejean, S., Gautier, B., Bartolo, F., et al. (2016). mixOmics: Omics Data Integration Project. $R$ Package Version 6.1.1.

Ledgards, F., and Steelek, W. (2016). Biological nitrogen fixation in mixed legume / grass pastures. Plant Soil 141, 137-153. doi: 10.1007/BF000 11314

Lisec, J., Schauer, N., Kopka, J., Willmitzer, L., and Fernie, A. (2006). Gas chromatography mass spectrometry-based metabolite profiling in plants. Nat. Protoc. 1, 387-396. doi: 10.1038/nprot.2006.59

Luedemann, A., Strassburg, K., Erban, A., and Kopka, J. (2008). TagFinder for the quantitative analysis of gas chromatography-mass spectrometry (GCMS)-based metabolite profiling experiments. Bioinformatics 24, 732-737. doi: 10.1093/bioinformatics/btn023

Luoga, E. J., Witkowski, E. T. F., and Balkwill, K. (2004). Regeneration by coppicing (resprouting) of miombo (African savanna) trees in relation to land use. For. Ecol. Manag. 189, 23-36. doi: 10.1016/j.foreco.2003. 02.001

Madams, R. W. (1990). The Biogeography of Colophospermum mopane (Kirk ex Benth.) Kirk ex J. Léon. At its Distribution Limit in Eastern Botswana. London: University of London.

MAE (2005). Perfil do Distrito de Massingir, Provincia de Gaza. Gaza City: Ministerio da Administracao Estatal.

Manderscheid, R., Jäger, H., and Kress, L. (1992). Effects of ozone on foliar nitrogen metabolism of Pinus taeda L. and implications for carbohydrate metabolism. New Phytol. 121, 623-633. doi: 10.1111/j.1469-8137.1992. tb01133.x

Mantlana, K. B. (2002). What Determine the Structure of Colophospermum mopane under Field Conditions in North-Western Botswana. Durban: University of Natal.

Martinelli, T., Whittaker, A., Bochicchio, A., Vazzana, C., Suzuki, A., and Masclaux-Daubresse, C. (2007). Amino acid pattern and glutamate metabolism during dehydration stress in the 'resurrection' plant Sporobolus stapfianus: a comparison between desiccation-sensitive and desiccation-tolerant leaves. J. Exp. Bot. 58, 3037-3046. doi: 10.1093/jxb/ erm 161
Mittler, R. (2006). Abiotic stress, the field environment and stress combination. Trends Plant Sci. 11, 15-19. doi: 10.1016/j.tplants.2005.11.002

Navashni, G., Ribeiro, N., Macandza, V., and Ruecker, G. (2015). Comparing Two Fire Management Regimes in the GLTP: Creating the Foundations for a Fire Management System in the LNP. Relatório do Trabalho de Investigação. Maputo: GIZ.

Neary, D. G., Ryan, K. C., and DeBano, L. F. (eds). (2008). Wildland Fire in Ecosystems: Effects of Fire on Soil and Water. General Technical Report RMRSGTR-42-vol.4. Ogden, UT: U.S. Department of Agriculture, Forest Service, Rocky Mountain Research Station, 250.

R Core Team (2016). R: A Language and Environment for Statistical Computing. $R$ Package Version 3.2.4. Vienna: R Foundation for Statistical Computing.

Raivo, K. (2015). pheatmap: Pretty Heatmaps. R Package Version 1.0.8.

Ribeiro, A., Romeiras, M., Tavares, J., and Faria, T. (2010). Ethnobotanical survey in Canhane village, district of Massingir, Mozambique: medicinal plants and traditional knowledge. J. Ethnobiol. Ethnomed. 6:33. doi: 10.1186/17464269-6-33

Ribeiro, N., Cumbana, M., Mamugy, F., and Chaúque, A. (2012). "Remote sensing of biomass in the miombo woodlands of Southern Africa: opportunities and limitations for research," in Remote Sensing of Biomass Principles and Applications, ed. D. L. Fatoyinbo (Rijeka: InTech), 7-98.

Ribeiro, N. S., Cangela A., Chauque, A., Bandeira, R. R., and Ribeiro-Barros, A. I. (2017). Spatial and temporal distribution of the fire regime in Niassa National Reserve, northern Mozambique. Int. J. Wildland Fire 26, 1021-1029. doi: 10.1071/WF17085

Sanchez, D., Siahpoosh, M., Roessner, U., Udvardi, M., and Kopka, J. (2008). Plant metabolomics reveals conserved and divergent. Physiol. Plant. 132, 209-219. doi: 10.1111/j.1399-3054.2007.00993.x

Shimazaki, K.-I., Nakamachi, K., Kondo, N., and Sugahara, K. (1984). Sulfite inhibition of Photosystem II in illuminated spinach leaves. Plant Cell Physiol. 25, 337-341.

Shulaev, V., Cortes, D., Miller, G., and Mittler, R. (2008). Metabolomics for plant stress response. Physiol. Plant. 132, 199-208. doi: 10.1111/j.1399-3054.2007. 01025.x

Smit, G. N., and Rethman, N. F. G. (1998). Root biomass, depth distribution and relations with leaf biomass of Colophospermum mopane. South Afr. J. Bot. 64, 38-43. doi: 10.1016/S0254-6299(15)30825-5

Solomon, A., Beer, S., Waisel, Y., Jones, G. P., and Paleg, L. G. (1994). Effects of $\mathrm{NaCl}$ on the carboxylating activity of Rubisco from Tamarix jordanis in the presence and absence of proline-related compatible solutes. Physiol. Plant. 90, 198-204. doi: 10.1111/j.1399-3054.1994.tb 02211.x

SRN (2005). Programa de Gestão e Desenvolvimento da Reserva Nacional do Niassa. Maputo: MICOA.

Stacklies, W., Redestig, H., Scholz, M., Walther, D., and Selbig, J. (2007). pcaMethods - a Bioconductor package providing PCA methods for incomplete data. Bioinformatics 23, 1164-1167. doi: 10.1093/bioinformatics/ btm069

Stalmans, M., Gertenbach, W., and Carvalho-Serfontein, F. (2004). Plant communities and landscapes of the Parque Nacional do Limpopo, Moçambique: Koedoe 47, 61-81.

Tanaka, Y., Iguchi, A., Nishida, K., Inoue, M., Nakamura, T., Suzuki, A., et al. (2014). Nutrient availability affects the response of juvenile corals and the endosymbionts to ocean acidification. Limnol. Oceanogr. 59, 1468-1476. doi: 10.4319/lo.2014.59.5.1468

Theerawitaya, C., Tisarum, R., Samphumphuang, T., Singh, H. P., Cha-Um, S., Kirdmanee, C., et al. (2015). Physio-biochemical and morphological characters of halophyte legume shrub, Acacia ampliceps seedlings in response to salt stress under greenhouse. Front. Plant Sci. 6:630. doi: 10.3389/fpls.2015. 00630

Torsethaugen, G., Pell, E. J., and Assmann, S. M. (1999). Ozone inhibits guard cell $\mathrm{K}+$ channels implicated in stomatal opening. Proc. Natl. Acad. Sci. U.S.A. 96, 13577-13582. doi: 10.1073/pnas.96.23.13577

Wellburn, A. R. (1985). " $\mathrm{SO}_{2}$ effects on stromal and thylakoid function," in Sulfur Dioxide and Vegetation, eds W. E. Winner, H. A. Mooney, and R. A. Goldstein (Stanford, CA: Stanford University Press). 
White, F. (1983). The Vegetation of Africa: A Descriptive Memoir to Accompany the UNESCO/AETFAT/UNSO, Vegetation Map of Africa (3 Plates). Paris: UNESCO.

WWF (2014). Miombo Eco-Region "Home of the Zambezi" Conservation Strategy 2011-2020. Harare: World Wide Fund for Nature.

Xu, G., Chen, J., and Liu, D. (2008). Mineral, Phenolic compounds and antioxidant capacity of citrus peel extract by hot water. J. Food Sci. 73, 545-551. doi: 10.1111/j.1750-3841.2007.00546.x

Yu, J., Hongmei, D., Ming, X., and Bingru, H. (2012). Metabolic responses to heat stress under elevated atmospheric $\mathrm{CO}_{2}$ concentration in a cool-season grass species. J. Am. Soc. Hortic. Sci. 137, 221-228.
Conflict of Interest Statement: The authors declare that the research was conducted in the absence of any commercial or financial relationships that could be construed as a potential conflict of interest.

Copyright $\odot 2017$ Duvane, Jorge, Maquia, Ribeiro, Ribeiro-Barros and António. This is an open-access article distributed under the terms of the Creative Commons Attribution License (CC BY). The use, distribution or reproduction in other forums is permitted, provided the original author(s) or licensor are credited and that the original publication in this journal is cited, in accordance with accepted academic practice. No use, distribution or reproduction is permitted which does not comply with these terms. 